\title{
一般口演11
}

\section{Sensory and pain perception in patients with myofascial pain of the jaw muscles}

\author{
OIchiro Okayasu ${ }^{1,2)}$, Kumiko $\mathrm{Oi}^{2)}$, Antoon De Laat ${ }^{1)}$ \\ 1) Department of Oral and Maxillofacial Surgery, School of Dentistry, Oral Pathology and Maxillofacial Surgery, \\ Catholic University of Leuven, Belgium \\ 2) Department of Clinical Physiology, Graduate School of Biomedical Sciences, Nagasaki University, Japan
}

\section{I. 目 的}

Out of a variety of measurement techniques of pain, e.g. subjective reporting ${ }^{1,2)}$, behavioral and physiologic responses, electromyographic recordings of jaw reflexes ${ }^{3-6)}$ and functional brain imaging, quantitative sensory testing is relatively easy to use and psychophysical procedures will hopefully allow us, to better objectify pain and dysfunction $^{7-10)}$.

Recently, we reported that in symptom-free subjects, a clenching exercise which is considered a possible risk factor in the development of orofacial pain ${ }^{11)}$ dose not result in extra modulation of tactile and pain thresholds in the face, what could be ascribed to habituation. It was striking that not only sensitivity to pain but also habituation of sensory perception were higher in women than $\operatorname{men}^{12)}$. Further exploration whether these effects are similar in patients suffering from myofascial pain of the jaw muscles might help to clarify the physiological reactions in patients developing pain and dysfunction.

The aim of this study was (1) to examine the effect of light tooth contact as in diurnal tooth clenching on the tactile detection threshold (TDT), the filament-prick pain detection threshold (FPT) and the pressure pain threshold (PPT) in the orofacial region of patients with myofascial pain of the jaw muscles and (2) to compare these effects to those in symptom free subjects.

\section{II. 方 法}

Up to now, the study was performed on 20 subjects: 10 control subjects and 10 patients with myofascial pain of the jaw muscles, as determined using the Research Diagnostic Criteria. Using a stair-case method, the TDT and the FPT were measured by means of Semmes-Weinstein monofilaments, on the cheek skin (CS) overlying the masseter muscles (MM) and on the skin overlying the palm side of the thenar muscle (Thenar Skin: TS). The PPT was measured at the central part of the MM using a pressure algometer.

Each parameter was measured before and after keeping light tooth contact for 5 minutes (session 1) and keeping the jaw relaxed for 5 minutes (session 2) as a control. The two measurements sessions were separated by 1 week and the order randomized.

The influence of the session (clenching or no clenching), the condition (before and after clenching or no clenching), and of case-control status was tested by ANOVA with repeated measures.

\section{III. 結果·考察}

There were no significant session effects on any of the parameters in both controls and patients.

There were, however, significant effects of experimental condition (before- after 5 minutes) on the TDT: after 5 minutes, the TDT was higher in all measurement sites except the left CS in the patients. No significant effects were observed regarding the FPT or the PPT. 
The increase of TDT after clenching / no clenching can be considered habituation. Habituation is a quite different reaction from sensitization; the former is a decrease or loss of response following repetitive stimulation and the latter is the increased excitability of reaction produced by trauma and inflammation of peripheral tissues which can be peripheral or central or both. In the present study, habituation was found in both patients with myofascial pain and control subjects. Case-control differences in habituation of sensory perception, however, were not found.

In order to obtain sufficient power to make these conclusions, both regarding sensory and pain perception, a bigger sample size, both in control subjects and patients with myofascial pain, is needed.

\section{IV. 文 献}

1) Jacobs $\mathrm{R}, \mathrm{Wu} \mathrm{CH}$, Van Loven $\mathrm{K}$, et al. Methodology of oral sensory tests. J Oral Rehabil 2002; 29: 720-730.

2) Komiyama O, De Laat A. Tactile and pain thresholds in the intra- and extra-oral regions of symptom-free subjects. Pain 2005; 115: 308-315.

3) van Steenberghe D, van der Glas HW, De Laat A, et al. The masseteric poststimulus EMG complex (PSEC) in man: methodology, underlying reflexes and clinical perspectives. In : Electromyography of jaw reflexes in man. van Steenberghe D, De Laat A, editors. Leuven: University Press; 1989, 269-288.
4) De Laat A, Svensson P, Macaluso GM. Are jaw and facial reflexes modulated during clinical and experimental orofacial pain? J Orofac Pain 1998; 12: 260-271.

5) Komiyama O, Wang K, Svensson P, et al. Exteroceptive suppression periods in masseteric EMG: Use of stimulus-response curves. Arch Oral Biol 2005; 50: 994-1004.

6) Torisu T, Wang K, Svensson P, et al. Effect of low-level clenching and subsequent muscle pain on exteroceptive suppression and resting muscle activity in human jaw muscles. Clin Neurophysiol 2007; 118: 999-1009.

7) Drobek W, De Laat A, Schoenaers. Tactile threshold and pressure pain threshold during treatment of orofacial pain: an explorative study. Clin Oral Invest 2001; 5: 185-193.

8) Isselee H, De Laat A, De Mot B, et al. Pressure-pain threshold variation in temporomandibular disorder myalgia over the course of the menstrual cycle. J Orofac Pain 2002; 16: 105-117.

9) De Laat A, Stappaerts K, Papy S. Counseling and physical therapy as treatment for myofascial pain of the masticatory system. J Orofac Pain 2003; 17: 42-49.

10) Michelotti A, Farella M, Stellato A, et al. Tactile and pain thresholds in patients with myofascial pain of the jaw muscles: A case-control study. J Orofac Pain 2008; 22: 139-145.

11) Chen CY, Palla $S$, Erni $S$, et al. Nonfunctional tooth contact in healthy controls and patients with myogeneous facial pain. J Orofac Pain 2007; 21: 185-193.

12) Okayasu I, Oi K, De Laat A. The tooth clenching on the sensory and pain perception in the oro-facial region of symptom-free men and women. J Oral Rehabil 2009; 36: 476-482. 